\title{
Newborn Hearing Screening in Neonates Exposed to Psychoactive Drugs
}

\author{
Bruna Salazar Castro da Rocha ${ }^{1}$ Márcia Salgado Machado ${ }^{2}$ Cláudia Fernandes Costa Zanini ${ }^{3}$ \\ Tatiana de Carvalho Paniz ${ }^{3}$ Isabela Hoffmeister Menegotto ${ }^{4}$
}

\footnotetext{
${ }^{1}$ Department of Phonoaudiology, Universidade Federal de Ciências da Saúde de Porto Alegre, UFCSPA, Porto Alegre, RS, Brazil

2 Department of Phonoaudiology, Universidade Federal de Santa

Maria, UFSM, Santa Maria, RS, Brazil

${ }^{3}$ Department of Phonoaudiology, Centro Especializado em

Fonoaudiologia Clínica, CEFAC, Porto Alegre, RS, Brazil

${ }^{4}$ Department of Phonoaudiology, Universidade Federal de São PauloUNIFESP, São Paulo, Brazil
}

Int Arch Otorhinolaryngol 2014;18:43-48.

\author{
Address for correspondence Bruna Salazar Castro da Rocha, \\ Graduation in Phonoaudiology, Rua Arnaldo Ballvê, 65 Bairro Jardim Itu \\ Sabará Porto Alegre-RS CEP 91380010, Brazil \\ (e-mail: brunascr@gmail.com).
}

\begin{abstract}
Keywords

- newborn screening

- psychotropic drugs

- hearing

Introduction In pregnancy, the mother and fetus share body structures based on the maternal organism. Exposure to psychoactive drugs in this period may have repercussions on the baby's hearing. Therefore, it is necessary to investigate this association. Aim Analyze the results of newborn hearing screening (NHS), the occurrence of associated risk factors, and the incidence of hearing loss in newborn exposed to psychoactive drugs during pregnancy.

Methods This is an observational retrospective study done from a database analysis. From this database, records were selected about the use of psychoactive drugs by mothers during pregnancy, then the neonates were divide into two groups: the study group (146 babies exposed to drugs) and the control group ( 500 babies not exposed to drugs). The NHS failure rate, the presence of risk factors for hearing loss, and need for audiological diagnosis were analyzed in both groups. From these variables, absolute frequency and prevalence rates were calculated and the results compared between groups.

Results There was no statistically significant difference in the comparison of NHS failure rates between the groups ( $p=0.267$ ). The occurrence of risk factors for hearing loss was greater in babies exposed to drugs $(p<0.0001)$. There was only one diagnosis of hearing loss, which occurred in the control group $(p=0.667)$.

Conclusion The use of psychoactive drugs by mothers during pregnancy did not affect the NHS failure rate of this sample. However, the occurrence of significant risk factors in the study group showed a possible sensitivity of babies exposed to psychoactive drugs during pregnancy.
\end{abstract}

\section{Introduction}

The development of hearing occurs gradually, beginning in intrauterine life. It is essential in child development of language and includes the ability to detect, find, discriminate, memorize, recognize, and comprehend sounds. All the devel- opmental steps of hearing are important and connected; therefore, the interruption of one or more of the steps induces important damage in the child. ${ }^{1}$

More than 800,000 children around the world have bilateral permanent loss hearing, either congenital or acquired. ${ }^{2}$ The newborn hearing screening (NHS) is essential to early received

May 4, 2013

accepted

August 4, 2013
DOI http://dx.doi.org/

10.1055/s-0033-1358579. ISSN 1809-9777.
Copyright ( $\odot 2014$ by Thieme Publicações License terms Ltda, Rio de Janeiro, Brazil

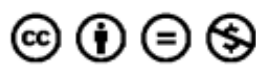


detection of hearing loss, a condition with serious vocational, educational, and social consequences. ${ }^{3}$ The earlier the hearing loss is diagnosed, the soon treatment can be started, reducing the damage on speaking and language development of the child and contributing to better social interaction. ${ }^{2,4}$

Psychoactive drugs are prejudicial to the organism of users, and use of these drugs during pregnancy can harm the fetus. ${ }^{5-7}$ Drug use can cause a global impact in the neonate's development, damaging growth of the central nervous system, and may bring on an alcoholic fetal syndrome, ${ }^{5}$ in addition to craniofacial malformations, hearing deficits, and prolonged interpeak on evoked hearing potentials. $^{6,7}$

However, the use of psychoactive drugs during pregnancy is not a risk factor for hearing loss, ${ }^{4}$ according to the Joint Committee of Infant Hearing (JCIH), 2007. ${ }^{8}$ This committee suggested the following risk factors for hearing loss: caregiver concern regarding delays on hearing, speaking, language, or development; familial history of permanent loss in childhood; intensive care of the neonate for more than 5 days; or any of the following occurrences, regardless of the permanence: extracorporeal membrane oxygenation, mechanic ventilation, exposure to ototoxic drugs or loop diuretics, and hyperbilirubinemia that requires exchange transfusion; in utero infections, craniofacial malformations, physical aspects such as white forelock that are associated with syndromes that include sensorineural hearing loss or permanent conductive hearing loss; syndromes associated with hearing loss, progressive or late hearing loss manifestation; neurodegenerative disorders or sensorimotor neuropathies; postnatal infections with positive culture associated with sensorineural hearing loss; head trauma; and chemotherapy.

The fact that psychoactive drugs use is not considered a risk factor for hearing loss by the $\mathrm{JCIH}, 2007^{8}$ probably justifies the lack of studies about hearing in children exposed to drugs during pregnancy. However, there is evidence of probable hearing alterations in exposed babies, such as a predisposition to secretory otitis media, with progressive loss

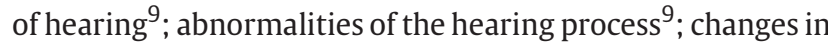
the formation of outer hair cells ${ }^{9}$; absolute latencies and prolonged interpeak ${ }^{7}$; less blood flow at the cochlea, which can cause a lower amplitude in the evoked potentials of hearing nerves ${ }^{7}$; and delay of hearing system maturation. ${ }^{5}$

In view of important sequelae of hearing deficits in infants and the possible relation between the use of psychoactive drugs during the gestational period and hearing loss occurrence, this study aims to analyze NHS results, the occurrence of associated risk factors, and the likely incidence of hearing deficit in neonates exposed to psychoactive drugs during pregnancy.

\section{Methods}

This observational retrospective study was done from a database analysis. The researched sample comes from the Hospital Materno Infantil Presidente Vargas (HMIPV), a public hospital from the south of Brazil, Porto Alegre's hospital reference to risk gestation. The study was approved by the
Ethics and Research Committee from HMIPV, no. 14/11 on July 13, 2011, and from Universidade Federal de Ciências da Saúde de Porto Alegre, no. 1658/12 on May 17, 2012. The Term Commitment to the Use and Disclosure of Data (suited for projects that use clinical data) was utilized; the study was ethically and methodologically appropriate according to the Guidelines and Standards of Research Involving Human (196/ 96 Resolution) from National Health Board.

The database is found in the HMIPV Internet portal. All NHS results, performed in outpatient, inpatient, or newborn intensive therapy unit (ITU) subjects, are registered in the database. The same is stored in Microsoft Excel file and updated by local audiologists, according to the actions taken for each baby.

This database was created from worksheets that had these items: date that the NHS was performed, mother's name, birth weight, gestational age, 1- and 5-minute Apgar scores, sex, medical observations, mother's registered use of drugs, place where NHS was performed, responsible audiologist, newborn situation in NHS protocol, test results and/or retest results, and/or NHS hearing results of each baby. The worksheets were filled out during each screening. If data were missing, they were added from physical records if possible.

For this database, the presence of a medical register about the use of psychoactive drugs by mothers between December 9, 2008, and December 29, 2011, was considered an inclusion factor; a total of 146 exposed babies were found (study group). Psychoactive drugs cited on the records were marijuana, crack, alcohol, tobacco, and cocaine, and at least one use was enough to consider a present exposition. Then 500 unexposed babies were selected (control group), randomly selected from an initial group of 2,578 unexposed babies. Sample size (study group and control group) was statistically calculated to support a $90 \%$ power, 5\% significance level, and $0.5 \%$ effect size of standard deviation between groups or a $20 \%$ difference. No NHS was considered an exclusion factor.

MADSEN AccuSCreen was used during this study. It analyzes the answers by an algorithmic statistical technique, allied to an artifact rejection system. The latter screens by transient otoacoustic emissions, by dispersion product, and also by automated auditory brainstem response (ABR) testing, which is the screening method chosen for each baby according to the suggested $\mathrm{JCIH}(2007)^{8}$ protocol, considering the risk factors for hearing loss.

The database was analyzed and organized based on the following variables: sex, presence or absence of risk factors for hearing loss, observations (when present, documented use of psychoactive drugs), first referral after NHS (retest, monitoring, or discharged), monitoring results (when realized), retest results (when realized), high complexity results (when realized), and final results with audiological diagnosis (when completed). Otoacoustic emissions test (OAE) and/or automated ABR test was used in the NHS. In both tests the possible results are pass (no alteration) and fail (with alteration). Discharge occurs when the baby passes through screening in both ears without risk factors for hearing loss. The retest is a new exam, done 15 days after NHS or according 
to the schedule availability of the service, after the baby has failed in at least one ear. Hearing monitoring is a new test that is done on newborns with risk factors for hearing loss 6 months after the original screening had been done and after the baby passed with both ears. Babies who failed the NHS retest are sent to high complexity services in the city, where audiological diagnosis can be performed through a complementary audiological evaluation. Sometimes it is not possible to perform the exam (any step: screening, retest, hearing monitoring, or diagnosis process) for specific reasons, such as baby agitation. In these cases, the procedure was documented as "impossible to test." When the baby did not show for the evaluation, the result was documented as "did not attend."

Absolute frequency analysis was done, and the prevalence of variables was studied (failure rate on newborn hearing screening process in children of mothers who were psychoactive drug users, risk factors present for hearing loss by JCIH, $2007,{ }^{8}$ and necessary referrals for the conclusion of audiological diagnosis) and compared with the same variables as control babies during pregnancy. The tests used were chisquare, Pearson, or Fisher exact test, with the Statistical Package for Social Sciences (SPSS) program, 17.0 version.

\section{Results}

From the initial sample of 146 babies from the study group and 500 babies from the control group, 72 babies were sent for retest, 20 (13.7\%) from the study group and 52 (10.4\%) from the control group; 130 for monitoring, 45 (30.8\%) from the study group and 85 (17\%) from the control group; and 444 were discharged, 81 (55.5\%) from the study group and 363 (72.6\%) from the control group.

-Fig. 1 presents the sample distribution relative to sex, showing a homogeneous sample in the study group and the control group ( $p=0.621)$.

-Fig. 2 shows the study group and the control group comparison relative to the presence of at least one risk factor for hearing loss $\left(\mathrm{JCIH}, 2007^{8}\right)$. Occurrence of hearing loss risk factors was significantly larger in the study group $(p<0.0001)$.

The NHS failure rate comparison between groups is shown in - Fig. 3; both groups were similar, although failure in the study group is slightly greater. Exposure to psychoactive

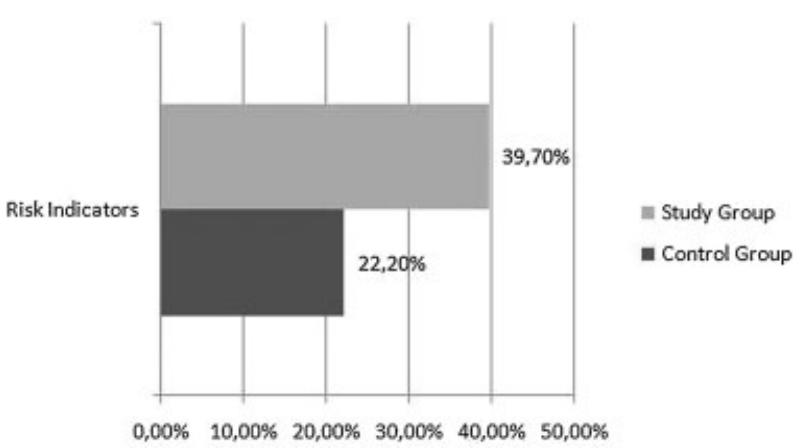

Fig. 2 Presence of risk factors in study and control groups $\left({ }^{*} p<0.0001\right)$.

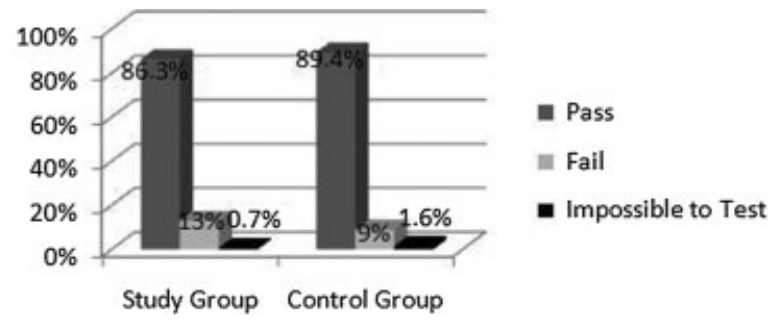

Fig. 3 Results of the newborn hearing screening in study group and control group $(p=0.267)$.

drugs during pregnancy was not a statistically significant factor to increased failure rate in the study group ( $p=0.267$ ).

-Fig. 4 shows the actions taken in the study group and the control group after the initial NHS. A greater prevalence of discharge in the control group and hearing monitoring in the study group can be seen; these tendencies reached statistical significance $(p<0.001)$. The retest rate was similar between groups $(p>0.05)$.

-Fig. 5 presents the actions taken because of hearing monitoring, 6 months after the initial NHS; the group comparison showed no statistically significant difference $(p=0.157)$.

The results obtained from retests after a failed NHS in the study and the control groups can be seen in - Table $\mathbf{1}$ and are similar between the groups ( $p=0.917)$.

-Fig. 6 illustrates the comparison between the final results of NHS process and audiological diagnoses in the

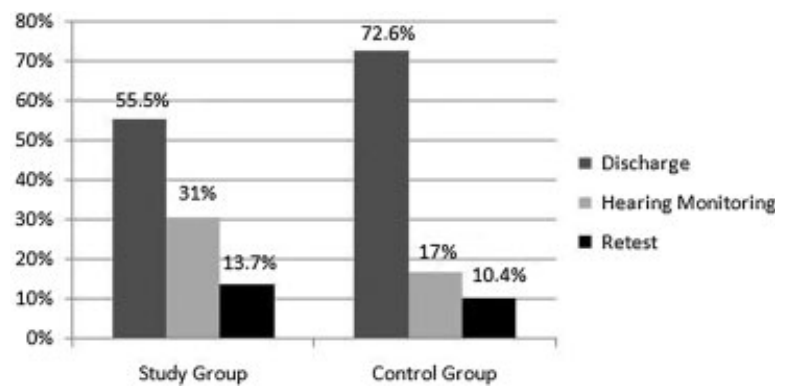

Fig. 4 Actions taken after initial newborn hearing screening in study and control groups $\left({ }^{*} p<0.001\right)$.

Fig. 1 Distribution of the sample in relation to $\operatorname{sex}(p=0.621)$. 


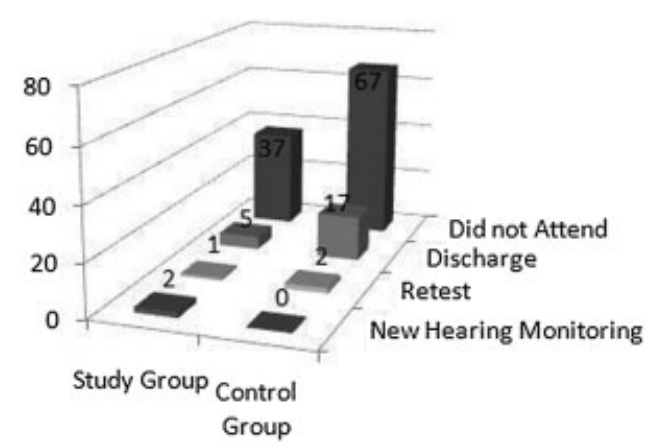

Fig. 5 Actions taken made from hearing monitoring in study and control groups $(p=0.157)$.

control group and the study group, showing again the similarity between the groups $(p=0.168)$.

Two babies in the study group were sent to high complexity services; one of them died and the other one obtained normal results on both ears. In the control group, there were four cases; two did not attend for diagnosis and two obtained unclear results, one compatible with otitis media. This comparison between the study and control groups was not statistically significant $(p=0.667)$.

\section{Discussion}

The present study compared NHS results, the occurrence of risk factors for hearing loss in babies exposed to psychoactive drugs during pregnancy, and the hearing loss case incidence, if present. The results showed that exposure to psychoactive drugs during the gestational period was not a differential factor to failing the NHS; there was no statistically significant difference between groups in this aspect $(p=0.267)$. However, the study group showed a higher tendency to fail the NHS (13\%) relative to the control group (9\%).

No specific studies were found in the literature that associated NHS failure rates and exposure to drugs during the gestational period. However, research demonstrated neurosensory hearing loss in 18 to $20 \%$ of rodents exposed to ethanol since day 7 of pregnancy, through $A B R .{ }^{10}$ In another study, absolute latencies and prolonged interpeaks on ABR were evidenced in children exposed to cocaine during the prenatal period. ${ }^{7}$ The literature also described alterations during auditory system formation, such as changed outer hair cells formation ${ }^{9}$ and decreased bloody flow on cochlea. ${ }^{7}$

In relation to the present study, it is believed that the absence of significant NHS failure in newborns exposed to

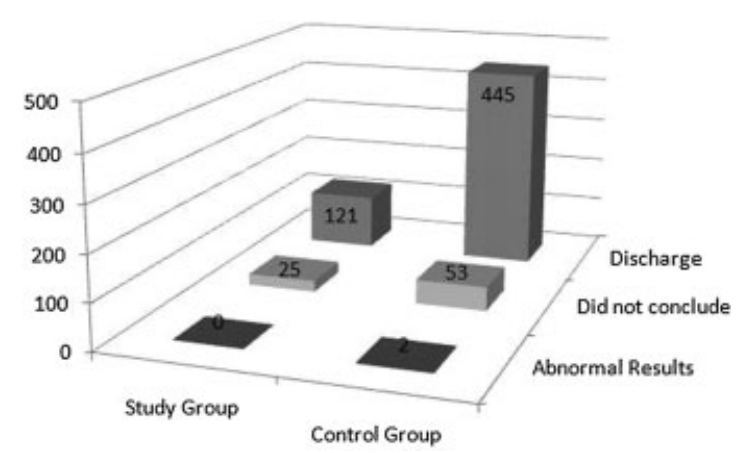

Fig. 6 Final result of newborn hearing screening and audiological diagnosis in study and control groups $(p=0.168)$.

psychoactive drugs during the gestational period can suggest three hypotheses. The first is an association with type, quantity, and frequency of drug use by the pregnant woman; this information could not be investigated in this sample. Beyond that, it was also considered that some newborns in the study group had mothers who reported only one episode of drug use, which might explain the absence of alterations on NHS, considering that the quantity of use may have been insufficient to damage the newborns' hearing system.

Another hypothesis is related to the possibility that psychoactive drugs are not directly involved in alterations on hearing structure, and that hearing alterations can occur in this population due to pre- or perinatal risk factors for infant hearing deficit, such as time in ITU of more than 5 days. It is known that these newborns can present prematurity, underweight, low Apgar scores, and other complications that require more time in the ITU, which could be the real cause of hearing deficits in this babies.

In this study, it was not possible in the database to discriminate babies who had different tests on NHS. The OAE points to answers on specific frequencies, generated on frequency bands where outer hair cells are normal or next to normal, ${ }^{11}$ and detects alterations from the cochlea. ${ }^{12}$ The ABR evaluates the auditory pathway integrity and auditory nerves to the brainstem. ${ }^{13,14}$ Not all babies had automatic ABR testing because the protocol at the collection place was followed, and this could be another reason for the nonoccurrence of significant difference on NHS failure rate between groups, as the literature reports neural alteration occurrence. $^{7,10}$ It is suggested that future studies search NHS results on babies exposed to drugs and standardize the type of test.

Table 1 Retest results performed after failure in the initial newborn hearing screening in study and control groups ( $p=0.917)$

\begin{tabular}{|l|l|l|l|l|l|l|}
\hline & Discharge & Hearing monitoring & New retest & High complexity & Did not attend & Total \\
\hline Study group & 11 & 3 & 1 & 2 & 3 & 20 \\
\hline Control group & 27 & 6 & 2 & 4 & 13 & 52 \\
\hline Total & 38 & 9 & 3 & 6 & 16 & \\
\hline
\end{tabular}


It was not viable to identify which psychoactive drugs each pregnant mother used in the present research, as well as the exposure time of each baby and the gestational period of drug abuse, because of the absence of this information $n$ database (previously structured). Studies describe the difficulty of quantifying the doses of respective psychoactive drug that are considered prejudicial and potential causers of fetal damage. $5,6,9,15$ This way, as the database used in this study had a great variety of drugs, without separation of consumed substance, such analysis and interpretation was not possible in this study.

The JCIH on Infant Hearing, $2007^{8}$ does not include psychoactive drug exposure during pregnancy as a risk for hearing loss. However, it was confirmed from this study that exposed babies had greater occurrence (39.7\%) of associated risk factors compared with unexposed babies (22.2\%), and this difference was statistically significant $(p<0.0001)$. This is an extremely relevant fact due to the evidence about drug exposition sensitizing the population to risk factor onset, as previously described. This aspect highlights the importance of hearing monitoring in this population; the incidence of hearing alterations on babies with risk factors can vary from 0.3 to $14.1 \%,{ }^{16}$ which is significantly greater than the hearing loss in eutrophic newborns.

It was not possible to list which risk factors were most prevalent in the study groups due to the sample size. So we decided to analyze this association in a future study.

Regarding the statistical difference observed in procedures after NHS, the control group had the greater discharge rate (72.60\%, $p<0,001)$ and the study group had a large rate of referrals to hearing monitoring (31\%, $p<0.001)$. It should be noted that discharge occurs when a baby goes through NHS and has no associated risk factors for hearing loss, and hearing monitoring occurs when a baby goes through NHS and has associated risk factors. This information reaffirms the previous premise about the need of continuous monitoring of these babies, emphasizing the importance of hearing monitoring.

Concerning hearing monitoring, a high nonattendance rate was found (82.2\% in the study group and $77.9 \%$ in the control group). Another study demonstrated a "great escape" commonly occurs when the individuals are sent for hearing monitoring. ${ }^{17}$ This evasion compromises the completion of the evaluation and its respective results. ${ }^{18,19}$ The disinterest and the difficulty of accessing the place where exams are performed is common, ${ }^{19}$ and mothers who use drugs tend to be of low socioeconomic status, use multiple drugs, have a family history of drug abuse, have a high occurrence of sexually transmitted diseases, not have prenatal exams, and also have depressive and paranoid characteristics. ${ }^{20}$ It is believed that the evasion to hearing monitoring in this study can be assigned to multiple factors, such as disinterest and the difficulty in local access where the exams are done, the mothers' drug use profiles, and association of both.

The high nonattendance rate observed also affects the study, because through hearing monitoring, complementary evaluations would be possible, for example, of hearing function development. Further studies should determine the incidence of hearing alterations on babies exposed to psychoactive drugs, as well as analyze the development of hearing maturation on this population.

Authors agree that it is an understudied topic ${ }^{5,6,9}$ and that there are still a lot of questions to be answered, like the safe dose of fetus exposure; hearing alteration pattern, when present; and which exams are more appropriate for hearing evaluation of newborns exposed to drugs during pregnancy.

Despite the small amount of referrals to the high complexity services, the difficulty to conclude the process was also evident, because even at the final stage of diagnosis patient abstention was considerable (in the two occurrences in the study group, one died and the other had normal results; in the four referrals in the control group, two did not show up and two had altered results). The high evasion rate was also confirmed at this stage of the process.

The results obtained in this study demonstrate the need for complementary investigation in babies exposed to psychoactive drugs during gestation, because the literature describes evidence about hearing alterations in these individuals. $7,9,10$ This study contributed with its findings mainly related to the higher occurrence of risk factors for hearing loss in the study group ( $p<0.0001$ ), the prevalence of hearing monitor referrals in the study group ( $p<0.001)$, and the high prevalence of discharges in the control group $(p<0.001)$.

Evidently, social work is needed for the effective accompaniment of these individuals, to decrease evasion rate and provide more answers and more concrete associations about child development. It is also important to highlight a suggestion for future studies investigating psychoactive drug exposition during pregnancy and the association with risk factors for hearing loss, in addition to the effects of each specific drug related to hearing.

\section{Conclusion}

In this study, newborns exposed to psychoactive drugs during the gestational period had a similar NHS failure rate as the control group. Concerning risk factors, it was shown that drug exposure provided a higher occurrence of risk factors for hearing loss. None of the babies exposed to drugs had hearing loss diagnosis, and in the control group, there was one diagnosed occurrence.

\section{References}

1 Marone SAM. Triagem auditiva neonatal. Braz J Otorhinolaryngol 2010;76(1):2-2

2 Meyer ME, Swanepoel W, le Roux T, van der Linde M. Early detection of infant hearing loss in the private health care sector of South Africa. Int J Pediatr Otorhinolaryngol 2012;76(5): 698-703

3 Garcia AP, Iório MCM, Petrilli AS. Monitoramento da audição de pacientes expostos à cisplatina. Rev Bras Otorrinolaringol 2003; 69(2):215-221

4 Ohl C, Dornier L, Czajka C, Chobaut JC, Tavernier L. Newborn hearing screening on infants at risk. Int J Pediatr Otorhinolaryngol 2009;73(12):1691-1695 
5 Person OC, Cerchiari DP, Moretti G, Zanini RVR, Monteiro TA, Rapoport PB. Repercussões auditivas da síndrome alcoólica fetal. Arq Med ABC 2005;30(2):94-101

6 Yamaguchi ET, Cardoso MMSC, Torres MLA, Andrade AGD. Drug abuse during pregnancy. Rev Psiquiatr Clin 2008;35(1):44-47

7 Nigri LF, Samelli AG, Schochat E. Potenciais evocados auditivos de tronco encefálico em usuários de crack e múltiplas drogas. Rev Soc Bras Fonoaudiol 2009;14(3):528-533

8 Joint Committee on Infant Hearing [Accessed on Feb, 2013]. Available at: http://www.jcih.org/posstatemts.htm

9 Cone-Wesson B. Prenatal alcohol and cocaine exposure: influences on cognition, speech, language, and hearing. J Commun Disord 2005;38(4):279-302

10 Church MW, Abel EL, Kaltenbach JA, Overbeck GW. Effects of prenatal alcohol exposure and aging on auditory function in the rat: preliminary results. Alcohol Clin Exp Res 1996;20(1):172-179

11 Souza LCA, Piza MRT, Alvarenga KF, Cóser PL. Emissões otoacústicas (EOA). In: Souza LCA, Piza MRT, Alvarenga KF, Cóser PL, eds. Eletrofisiologia da Audição e Emissões Otoacústicas Princípios e Aplicações Clínicas. 2a ed. Ribeirão Preto, Brasil: Editora Novo Conceito Saúde; 2010:109-130

12 Pialarissi PR, Gattaz G. Emissões otoacústicas: conceitos básicos e aplicações clínicas. Int Arch Otorhinolaryngol 1997;1(2):13

13 Matas CG, Leite RA, Gonçalves IC, Neves IF. Brainstem auditory evoked potential in individuals with conductive and sensorineural hearing losses. Int Arch Otorhinolaryngol 2005;9(4):337
14 Souza LCA, Piza MRT, Alvarenga KF, Cóser PL. Potencial Evocado Auditivo de Tronco Encefálico (PEATE). In: Souza LCA, Piza MRT, Alvarenga KF, Cóser PL, eds. Eletrofisiologia da Audição e Emissões Otoacústicas Princípios e Aplicações Clínicas. $2^{\underline{a}}$ ed. Ribeirão Preto, Brasil: Editora Novo Conceito Saúde; 2010:49-87

15 Carvalho ACA, Rocha RS, Pereira ES, et al. O uso de drogas psicotrópicas na gestação. Femina 2009;37(6):331-338

16 Botelho FA, Bouzada MCF, Resende LM, Silva CFX, Oliveira EA. Prevalence of hearing impairment in children at risk. Braz J Otorhinolaryngol 2010;76(6):739-744

17 Peixoto LAS, Lewis RD, Almeida GM, Silva GLP. Monitoramento Audiológico em um grupo de crianças com indicadores de risco para deficiência auditiva: dificuldades e caracterização audiológica. $26^{\circ}$ Encontro Internacional de Audiologia. 2011. [Accessed on April 12, 2013] Available at: http://www.audiologiabrasil.org.br/ eiamaceio2011/anais_select.php?eia=\&pg=poster\&cid=3045

18 Liu CL, Farrell J, MacNeil JR, Stone S, Barfield W. Evaluating loss to follow-up in newborn hearing screening in Massachusetts. Pediatrics 2008;121(2):e335-e343

19 Alvarenga KF, Gadret JM, Araújo ES, Bevilacqua MC. Triagem auditiva neonatal: motivos da evasão das famílias no processo de detecção precoce. Rev Soc Bras Fonoaudiol 2012;17(3): 241-247

20 Corradini HB. Cocaína: Efeitos na Gestante e nas Crianças. Pediatria (São Paulo) 1996;18(2):170-174 